\title{
An Evolutionary Game Analysis of Synergetic Innovation behaviour in regional innovation networks
}

\author{
Dong $\mathrm{Li}^{1}$, Chunyan $\mathrm{Liu}^{1,2^{*}}$ \\ 1. School of Economics and Management, Southeast University, Nanjing 210096, Jiangsu, China; \\ 2. School of Economic Management, Lanzhou University of Technology, GanSu, LanZhou 730050, China
}

\begin{abstract}
Regional innovation network has become an important way to improve national independent innovation ability and promote regional and social development. This paper studies the evolution of the synergetic innovation system of industry-university-Research Collaboration under the government behaviour, constructs an asymmetric evolutionary game model between the government and industry-universityResearch collaboration, and analyses the influence of parameter changes on synergetic innovation decisionmaking behaviour. The results showed that the government's regulatory costs ,subsidies from the government , the production, will take the profit resulting from the synergetic innovation behavior ,coordination costs and government punishment, and one party to the cooperative behaviour decision to bring the other side of the loss factors such as size ,to participate in Innovation decision-making behaviour of the subject of dynamic evolution path and the results have important influence to the use of MATLAB software evolution paths of related factors under different conditions and the trend of simulation test and verify .
\end{abstract}

\section{Introduction}

High-quality economic development must rely on innovation. Kamla Ali al-Busaidi and Lorne Olfman (2016) [1] believe that sharing knowledge through knowledge sharing network is conducive to improving innovation performance. Cooke and Uranga (1992) put forward the concept of "regional innovation system" for the first time [2], pointing out that regional innovation system is a system that realizes the interaction between enterprises and university research institutes by combining regional resources ,social capital and other factors [3]. According to Saxenian's research on Silicon Valley, regional innovation networks promote collective learning and knowledge transfer among innovation subjects [4]. Lee, Olson and Trimi et al. [5] believe that the development from closed innovation, cooperative innovation and open innovation to collaborative innovation is a new paradigm of innovation. Collaborative innovation is the integration of new ideas and methods from internal and external sources of innovation into the platform to generate new organizations and values. Therefore, the collaborative innovation research of regional innovation network has certain practical significance. From the 1990s to the present ,research achievements of regional collaborative innovation mainly focus on the factors influencing regional collaborative innovation ability [6-7], the operation mechanism and mechanism of regional collaborative innovation [8,9], regional collaborative innovation alliance, model and performance [10, 11, 12], etc. From the perspective of cost and benefit, this paper studies the evolution of the collaborative innovation system of industry-university-Research collaboration under the government behaviour.

\section{Model Construction}

\subsection{Basic Assumptions}

Hypothesis 1: There are three types of main participants in the regional innovation network, namely, the government, enterprises, universities and research institutes. Their decision-making behaviour is bounded rationality.

Hypothesis2: In the synergetic Innovation game, the participants need to play games for many times. The optimal strategy will not be reached once, but the players will gradually seek for the optimal strategy through constant communication and trial and error adjustment.

Hypothesis3: The strategy choice of government is \{supervision, non-supervision\}, while the strategy choice of the enterprise and the research party is \{coordination, non-coordination $\}$. Knowledge and technology are the key factors of synergetic Innovation [13]. Among them, synergetic innovation refers to that enterprises and universities and research institutes among regional innovation subjects actively engage in knowledge sharing and technical cooperation in order to achieve the development of regional innovation ability. Noncollaborative innovation refers to that enterprises and universities and research institutes among regional 
innovation subjects only meet the cooperation requirements of the lowest level, but do not actively engage in knowledge sharing and technical cooperation. Suppose that at the beginning of the game, the probability of government choosing supervision is $\mathrm{Z}$, the probability of non-supervision is $1-z$, the probability of enterprise choosing synergetic Innovation is $\mathrm{X}$, the probability of non-collaborative innovation is $1-\mathrm{x}$, the probability of academic research party choosing synergetic Innovation is $\mathrm{Y}$, and the probability of non-collaborative innovation is $1-\mathrm{y}, \quad 0 \leq x, y, z \leq 1$.

Hypothesis4: When both enterprises and universities and research institutes choose the synergetic Innovation strategy, a certain cost $\mathrm{C}$ is required to construct the synergetic Innovation system, and the cost distribution coefficient is $\alpha$, the enterprise input cost is $\alpha C$, the input cost of the research party is $(1-\alpha) C$. Due to market risk, the enterprise and the research of party building in synergetic Innovation system, the degree of market risk depends on both sides of the synergy degree, coordination degree and coordination degree, namely, relation between market is inversely proportional risk, the higher the market risk is smaller, a market risk coefficient for f, synergy degree for $h$, the enterprises and research of the risk coefficient for $\mathrm{f}-\mathrm{h}$. Then the synergetic innovation cost of the enterprise is $(f-h) \alpha C$. The synergetic innovation cost of university-research party is $(f-h)(1-\alpha) C$. In the development of regional innovation ability, enterprises play the role of taking social responsibility of talent training and enhancing regional employment rate, and the government gives preferential policies or subsidies G1. Similarly, universities and research institutes, as participants in regional innovation, provide knowledge and technology reserves for regional innovation, and the government gives preferential policies or subsidies for G2. In the process of synergetic innovation, knowledge spillover and technological innovation are the key factors that determine synergetic innovation [14-15]. The technological innovation input of enterprises and universities and research parties is V1 and V2, and the knowledge spillover benefit is $\gamma$. Then the profits of the enterprise and the research party are respectively ${ }_{1}+\gamma V_{1}$, $V_{2}+\gamma V_{2}[16]$.

Hypothesis5: When both the enterprise and the university and research party choose not to cooperate with the innovation strategy, R1 and R2 are the benefits that the enterprise and the university and research party obtain by independent innovation based on their own capabilities. Moreover, the input cost of independent innovation is $\mathrm{C} 1$ and $\mathrm{C} 2$, and the market risk coefficient faced by independent innovation is $\mathrm{F}$, so the cost of independent innovation of enterprises and research parties is $\mathrm{fC} 1$ and $\mathrm{fC} 2$. In order to promote the development of regional innovation and improve the economic capacity of the region, the government will punish enterprises that do not cooperate in innovation by means of punishment, which are $\mathrm{L} 1$ and $\mathrm{L} 2$ respectively.

Hypothesis6: When the enterprise and the research institute do not cooperate with each other, they cannot obtain synergies, but can obtain basic benefits R1 and R2. In addition, the non-cooperative innovator who adopts opportunistic behavior will get additional benefits, which are recorded as D1 and D2 respectively. If the enterprise fails to make collaborative innovation, the loss to the enterprise is W1; similarly, the loss to the enterprise fails to make synergetic innovation is W2. The penalties are still L1 and L2.

Hypothesis7: The game, in addition to the enterprise and government to rewards and punishments, and research and to supervise and monitor the decision to choose, when the government choose monitoring strategy takes the supervision of the cost of $\mathrm{F}$, but at the same time because of the supervision behavior can bring economic benefits, improve the capacity of science and technology achievements conversion rate etc., set up enterprises and at parties shall take the economic benefits of synergetic innovation for E. If only the enterprise adopts the synergetic innovation strategy, the revenue obtained by the government is $\mathrm{N} 1$, and if only the university and research company adopts the synergetic innovation strategy, the revenue obtained by the government is N2 parameter which is greater than 0 . Based on the above assumptions, the revenue matrix of the cooperative innovation game model of the three parties is shown in Table 1 below:

Table1. the revenue matrix of the cooperative innovation game model of the three parties

\begin{tabular}{|c|c|c|c|c|c|}
\hline & & \multicolumn{4}{|l|}{ enterprise } \\
\hline & & \multicolumn{2}{|c|}{ Synergetic Innovation $x$} & \multicolumn{2}{|c|}{ Non-Synergetic Innovation (1-x) } \\
\hline & & \multicolumn{4}{|c|}{ the university and research institute } \\
\hline & & $\begin{array}{l}\text { Synergetic } \\
\text { Innovation y }\end{array}$ & $\begin{array}{l}\text { Non-Synergetic } \\
\text { Innovation (1-y) }\end{array}$ & $\begin{array}{l}\text { Synergetic } \\
\text { Innovation y }\end{array}$ & $\begin{array}{l}\text { Non-Synergetic } \\
\text { Innovation(1-y) }\end{array}$ \\
\hline \multirow{2}{*}{ Government } & $\begin{array}{c}\text { Supervise } \\
\mathrm{z}\end{array}$ & $\begin{array}{c}\mathrm{E}-\mathrm{G}_{1}-\mathrm{G}_{2}-\mathrm{F} \\
\mathrm{R}_{1}+\left(v_{1}+\gamma_{1}\right)+\mathrm{G}_{1}-(\mathrm{f}-\mathrm{h}) \alpha C \\
\mathrm{R}_{2}+\left(v_{2}+\gamma_{2}\right)+\mathrm{G}_{2}-(\mathrm{f}-\mathrm{h})(1-\alpha) C\end{array}$ & $\begin{array}{c}\mathrm{N}_{1}+\mathrm{L}_{2}-\mathrm{G}_{1}-\mathrm{F} \\
\mathrm{R}_{1}+\mathrm{G}_{1}-\mathrm{W}_{1}-\mathrm{fC}_{1} \\
\mathrm{R}_{2}+\mathrm{D}_{2}-\mathrm{L}_{2}\end{array}$ & $\begin{array}{c}\mathrm{N}_{2}+\mathrm{L}_{1}-\mathrm{G}_{2}-\mathrm{F} \\
\mathrm{R}_{1}+\mathrm{D}_{1}-\mathrm{L}_{1} \\
\mathrm{R}_{2}+\mathrm{G}_{2}-\mathrm{W}_{2}-\mathrm{fC}_{2}\end{array}$ & $\begin{array}{l}\mathrm{L}_{1}+\mathrm{L}_{2}-\mathrm{F} \\
\mathrm{R}_{1}-\mathrm{L}_{1} \\
\mathrm{R}_{2}-\mathrm{L}_{2}\end{array}$ \\
\hline & $\begin{array}{l}\text { No } \\
\text { Supervise } \\
(1-z)\end{array}$ & $\begin{array}{c}\mathrm{E} \\
\mathrm{R}_{1}+\left(\nu_{1}+\psi_{1}\right)-(\mathrm{f}-\mathrm{h}) \alpha C \\
\mathrm{R}_{2}+\left(\zeta_{2}+\gamma_{2}\right)-(\mathrm{f}-\mathrm{h})(1-\alpha) C\end{array}$ & $\begin{array}{c}\mathrm{N}_{1} \\
\mathrm{R}_{1}+\mathrm{G}_{1}-\mathrm{fC}_{1} \\
\mathrm{R}_{2}+\mathrm{D}_{2}\end{array}$ & $\begin{array}{c}\mathrm{N}_{2} \\
\mathrm{R}_{1}+\mathrm{D}_{1} \\
\mathrm{R}_{2}-\mathrm{W}_{2}-\mathrm{fC}_{2}\end{array}$ & $\begin{array}{l}0 \\
\mathrm{R}_{1} \\
\mathrm{R}_{2}\end{array}$ \\
\hline
\end{tabular}

\section{2 model analysis}

According to the hypothesis, the enterprises choose the expected return of innovation strategy are as follows: 
$\mathrm{U} 11=\mathrm{yz}\left[\mathrm{R} 1+\left({ }^{V_{1}+\gamma V_{1}}\right)+\mathrm{G} 1-(\mathrm{f}-\mathrm{h}) \alpha C\right]+(1-\mathrm{y}) \mathrm{z}(\mathrm{R} 1+\mathrm{G} 1-$ $\mathrm{W} 1-\mathrm{fC} 1)+\mathrm{y}(1-\mathrm{z})\left[\mathrm{R} 1+\left({ }^{V_{1}+\gamma_{1}}\right)-(\mathrm{f}-\mathrm{h}) \alpha C\right]+(1-\mathrm{y})(1-\mathrm{z})(\mathrm{R} 1+\mathrm{G} 1-$ $\mathrm{fC} 1)$

The expected benefits of non-synergetic innovation strategy are as follows:

$\mathrm{U} 12=\mathrm{yz}(\mathrm{R} 1+\mathrm{D} 1-\mathrm{L} 1)+(1-\mathrm{y}) \mathrm{z}(\mathrm{R} 1-\mathrm{L} 1)+\mathrm{y}(1-\mathrm{z})(\mathrm{R} 1+\mathrm{D} 1)+(1-$ y)(1-z) R1

The average expected earnings of the enterprise are: $\mathrm{U} 1=\mathrm{x} \mathrm{U} 11+(1-\mathrm{x}) \mathrm{U} 12$

Therefore, the replication dynamic equation of the enterprise is:

$$
\begin{aligned}
& F(x)=\frac{d x}{d t}=x\left(U_{11}-U_{1}\right)=x(1-x)\left(U_{11}-U_{12}\right) \\
& =x(1-x)\left[y z\left[\left(V_{1}+\gamma V_{1}\right)+G_{1}-(f-h) \alpha C-D_{1}+L_{1}\right]+(1-y) z\left(G_{1}-W_{1}-f C_{1}+L_{1}\right)\right. \\
& \left.+y(1-z)\left[\left(V_{1}+\gamma V_{1}\right)-(f-h) \alpha C-D_{1}\right]+(1-y)(1-z)\left(G_{1}-f C_{1}\right)\right]
\end{aligned}
$$

The expected benefits of the synergetic innovation strategy chosen by the university and research institute are as follows:

$$
\begin{aligned}
& \mathrm{U} 21=\mathrm{xz}\left[\mathrm{R} 2+\left(\begin{array}{c}
V_{2}+\gamma V_{2} \\
\mathrm{f}
\end{array}\right) \mathrm{G} 2-(\mathrm{f}-\mathrm{h})\right. \\
& \mathrm{fC} 2)+\mathrm{x}(1-\mathrm{z})\left[\mathrm{R} 2+\left({ }^{V_{2}}+\gamma V_{2}\right)\right. \\
& -(\mathrm{f}-\mathrm{h})(1-\alpha) C]+(1-\mathrm{x})(1-\mathrm{z})(\mathrm{R} 2-\mathrm{W} 2-\mathrm{fC} 2)
\end{aligned}
$$

The expected benefits of the non-synergetic innovation strategy chosen by the university and research institute are:

$$
\mathrm{U} 22=\mathrm{xz}(\quad \mathrm{R} 2+\mathrm{D} 2-\mathrm{L} 2)+(1-\mathrm{x}) \mathrm{z} \quad(\mathrm{R} 2-\mathrm{L} 2)+\mathrm{x}(1-
$$
$\mathrm{z})(\mathrm{R} 2+\mathrm{D} 2)+(1-\mathrm{x})(\mathrm{1}-\mathrm{z}) \mathrm{R} 2$

At the average expected return for: $\mathrm{U} 2=\mathrm{yU} 21+\mathrm{U} 22$ (1- y)

Similarly, the replication dynamic equation of the university and research institute is:

$$
F(y)=\frac{d y}{d t}=y\left(U_{21}-U_{2}\right)=y(1-y)\left(U_{21}-U_{22}\right)
$$

$=y(1-y)\left[x z\left[\left(V_{2}+\gamma V_{2}\right)+G_{2}-(f-h)(1-\alpha) C-D_{2}+L_{2}\right]+(1-x) z\left(G_{2}-W_{2}-f C_{2}+L_{2}\right)\right.$

$\left.+x(1-z)\left[\left(V_{2}+\gamma V_{2}\right)-(f-h)(1-\alpha) C-D_{2}\right]+(1-x)(1-z)\left(-W_{2}-f C_{2}\right)\right]$

The expected benefits of the government's regulatory strategy selection are:

$\mathrm{U} 31=\mathrm{xy}(\mathrm{E}-\mathrm{G} 1-\mathrm{G} 2-\mathrm{F})+\mathrm{x}(1-\mathrm{y})(\mathrm{N} 1+\mathrm{L} 2-\mathrm{G} 1-\mathrm{F})+(1-\mathrm{x}) \mathrm{y}(\mathrm{N} 2+\mathrm{L} 1-\mathrm{G} 2-\mathrm{F})+(1-$ $\mathrm{x})(1-\mathrm{y})(\mathrm{L} 1+\mathrm{L} 2-\mathrm{F})$

The expected benefits of the government's nonregulatory strategy are:

$\mathrm{U} 32=\mathrm{xyE}+\mathrm{x}(1-\mathrm{y}) \mathrm{N} 1+(1-\mathrm{x}) \mathrm{yN} 2$

The average expected government revenue is: $\mathrm{U} 3=\mathrm{zU} 31+(1-\mathrm{z}) \mathrm{U} 32$

Similarly, the government's replication dynamic equation is:

$F(z)=\frac{d z}{d t}=z\left(U_{31}-U_{3}\right)=z(1-z)\left(U_{31}-U_{32}\right)$

$=z(1-z)\left[x y\left(-G-G_{2}-F\right)+x(1-y)\left(L_{2}-G_{1}-F\right)+(1-x) y\left(L_{1}-G_{2}-F\right)+(1-x)(1-y)\left(L_{1}+L_{2}-F\right)\right]$

A three-dimensional dynamic system can be obtained by copying dynamic equations of simultaneous enterprises, academic research institute and government. This system can describe the evolution dynamics of the three groups, and let $\mathrm{F}(\mathrm{x})=\mathrm{F}(\mathrm{y})=\mathrm{F}(\mathrm{z})=0$. The equilibrium point of the governmentindustry-University-Research evolutionary game system is obtained and the equilibrium point of the system is: $\mathrm{E} 1(0,0,0)$, $\mathrm{E} 2(0,0,1) 、 \mathrm{E} 3(0,1,0) 、 \mathrm{E} 4(0,1,1) 、 \mathrm{E} 5(1,0,0) 、 \mathrm{E} 6(1,0,1)$ 、

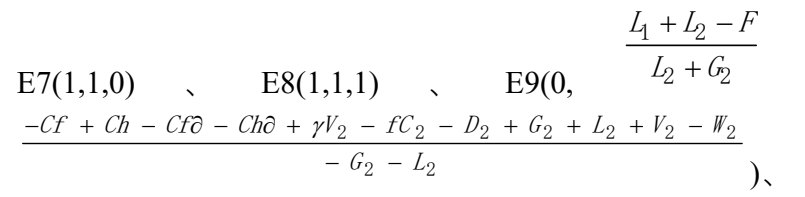

$$
\begin{aligned}
& \operatorname{E10}\left(1, \quad \frac{G_{1}+2 L_{1}+L_{2}+F}{L_{2}+G_{2}}\right. \\
& \frac{-2 C f+2 C h+2 C f \partial-2 C h \partial+2 \gamma V_{2}+2 V_{2}-2 D_{2}+G_{2}+L_{2}}{-C f+C h+C f \partial-C h \partial+\gamma V_{2}+V_{2}-D_{2}} \\
& \text { E11( } \left.-\frac{F-L_{2}-L_{1}}{G+L_{1}}, 0,-\frac{G_{1}+f C_{1}}{-W_{1}+L_{1}}\right) 、 \text { E12( }-\frac{F-G_{2}-L_{1}}{G+L_{1}}, 1, \\
& \frac{\partial C f-\partial C h-\gamma V_{1}-V_{1}+D_{1}}{G_{1}+L_{1}} \\
& \text { E13( } \\
& \frac{W_{2}-V_{2}-L_{2}-G_{2}+D_{2}+f C_{2}-\gamma V_{2}+C h \alpha-C f \alpha-C h+C f}{-C f+C h+C f \alpha-C h \alpha+W_{2}+V_{2}-D_{2}+f C 2+\gamma V_{2}} \\
& -\frac{-G_{1}+f C_{1}}{\partial C f-\alpha C h-f C_{1}-\gamma V_{1}+G_{1}-V_{1}+D_{1}}, \\
& \mathrm{E} 14( \\
& \frac{-2 G_{2}-2 L_{2}+W_{2}-V_{2}+D_{2}+f C_{2}-\gamma V_{2}+C h \alpha-C f \alpha-C h+C f}{W_{2}+f C_{2}-L_{2}-G_{2}} \\
& \frac{L_{1}-W_{1}-f C_{1}+G_{1}}{\alpha C f-\alpha C h-f C_{1}-\gamma V_{1}-V_{1}+D_{1}-W_{1}}
\end{aligned}
$$

,1).

According to literature [17], the equilibrium point of evolutionary game is asymptotically stable, which needs to meet the condition of pure strategic Nash equilibrium. Therefore, in the evolutionary game system of government-industry-university-Research synergetic innovation behavior, E1-E8 is asymptotically stable, and the rest points are not asymptotically stable. Therefore, only the eight points of E1-E8 are discussed. E1-E8 is according to the jacobian local stability analysis method, the stability of the 8 equilibrium points of judged. Therefore, the Jacobian matrix of the evolutionary game composed of enterprises, universities and research parties and governments is $\mathrm{J}$ :

$$
\mathbf{J}=\left[\begin{array}{lll}
\frac{d x / d t}{d x} & \frac{d x / d t}{d y} & \frac{d x / d t}{d z} \\
\frac{d y / d t}{d x} & \frac{d y / d t}{d y} & \frac{d y / d t}{d z} \\
\frac{d z / d t}{d x} & \frac{d z / d t}{d y} & \frac{d z / d t}{d z}
\end{array}\right]
$$

The values in the Jacobian matrix are as follows:

When $E 1=(0,0,0)$, the jacobian matrix of the evolutionary game system is:

$$
\left[\begin{array}{ccc}
G_{1}-f C_{1} & 0 & 0 \\
0 & V_{2}+\gamma V_{2}+G_{2}-(f-h)(1-\alpha) C-D_{2}+L_{2}-W_{2}-f C_{2} & 0 \\
0 & 0 & L_{1}+L_{2}-F
\end{array}\right]
$$

Similarly, the Jacobian matrix of the evolutionary game system synergetic innovation can also be obtained at other points.

\section{Simulation}

According to literature [17], the stability of each equilibrium point is determined by the positive and negative eigenvalues obtained from the linear homogeneous equation corresponding to the Jacobian matrix of each equilibrium point. When the eigenvalues of each equilibrium point are negative, the point is an evolutionary stable strategy (ESS), Otherwise, it is 
regarded as unstable point. However, according to the jacobian matrices obtained above, the positive and negative eigenvalues depend on the equivalence of $\mathrm{G} 1$ and $\mathrm{C} 1$. Therefore, the variable that affects the eigenvalue symbol is assigned as: $\mathrm{F}=3, \mathrm{G} 1=4, \mathrm{G} 2=3, \mathrm{~L} 1=1.5, \mathrm{~L} 2=1$, $\mathrm{V} 1=2, \mathrm{~V} 2=1.5, \mathrm{C}=4, \mathrm{C} 1=3, \mathrm{C} 2=3, \mathrm{D} 1=5, \mathrm{D} 2=4, \mathrm{~W} 1=2$, $\mathrm{W} 2=1, \gamma=0.6, \mathrm{f}=0.8, \mathrm{~h}=0.7, \alpha=0.6$. The stability analysis of each point is shown in Table 2 on the next page.

The table 2 shows that political study evolutionary game system consisting of three parties in an evolutionary stable strategy (synergetic innovation, cooperative innovation, not regulation), the evolutionary stable strategy shows that regardless of the initial enterprise and at parties choose what kind of strategy, after a period of trials, exploration, enterprise and eventually at party can choose cooperative innovation strategy, build synergy innovation system.

For the government, its best strategy is not to regulate, that is, to let go boldly, and let enterprises and universities and research institutes innovate according to their own actual conditions.

Table2. Stability analysis of each equilibrium point

\begin{tabular}{cll}
\hline equilibrium point & \multicolumn{1}{c}{ Eigenvalue symbol } & stability \\
\hline E1 $(0,0,0)$ & There are nonnegative eigenvalues & Instability point \\
E2(0,0,1) & There are nonnegative eigenvalues & Instability point \\
E3(0,1,0) & There are nonnegative eigenvalues & Instability point \\
E4(0,1,1) & There are nonnegative eigenvalues & Instability point \\
E5(1,0,0) & There are nonnegative eigenvalues & Instability point \\
E6(1,0,1) & There are nonnegative eigenvalues & Instability point \\
E7(1,1,0) & All are non-negative eigenvalues & ESS \\
E8(1,1,1) & There are nonnegative eigenvalues & Instability point \\
\hline
\end{tabular}

Although the government's best strategy is nonregulation, the government's subsidies and penalties for non-synergetic innovation have an impact on the decision making of enterprises and research institutes. The government can moderately increase the subsidy policy and adjust the punishment measure, to promote the decision-making behavior of the nodes of the regional system, and then increase the probability of building synergetic innovation to promote the regional economic development. The phase diagram of the evolution game of the three groups of government, enterprises, university and research institute is obtained through simulation, as shown in Figure 1 below.

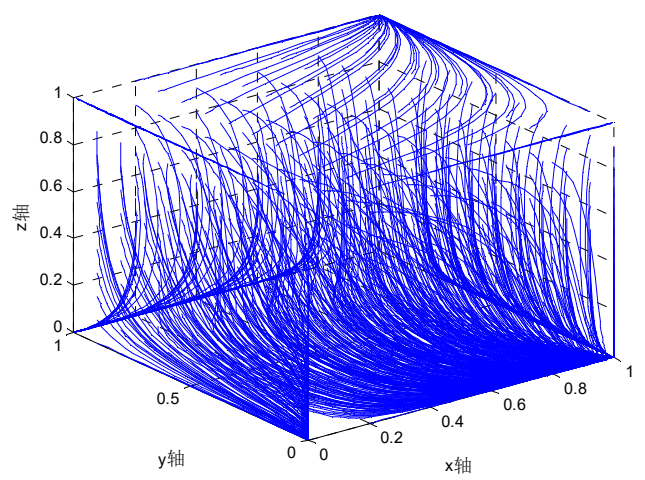

Fig1. Phase diagram of a three-group evolutionary game

It can be seen from FIG. 1 that, regardless of the initial probability $(\mathrm{x}, \mathrm{y}, \mathrm{z})$ of the three groups ,under the hypothetical parameter of this paper, the ultimate population evolution path of the government is unregulated,while that of the enterprise and the three groups is synergetic innovation, that is, the ultimate evolutionary stability strategy is $\operatorname{ESS}(1,1,0)$.

To further verify the above conclusion, when the initial value is $(0.1,0.3,0.8)$, the evolution phase diagram of the three populations is shown in Figure 2 on next page.

It can be seen from FIG. 2 that, given an initial value, enterprises and research institutes will eventually tend to synergetic innovation over time, while the government would tend not to regulate. This is what the government wants to see the situation for production. The government expects enterprises to innovate according to their actual needs and make the most of marketization, but that doesn't mean the government will completely ignore regulation. The government still needs to provide certain policy support and reward and punishment mechanism, and encourage the standardization, marketization and scale of collaborative innovation behaviors, thus leading to the development of regional economy.
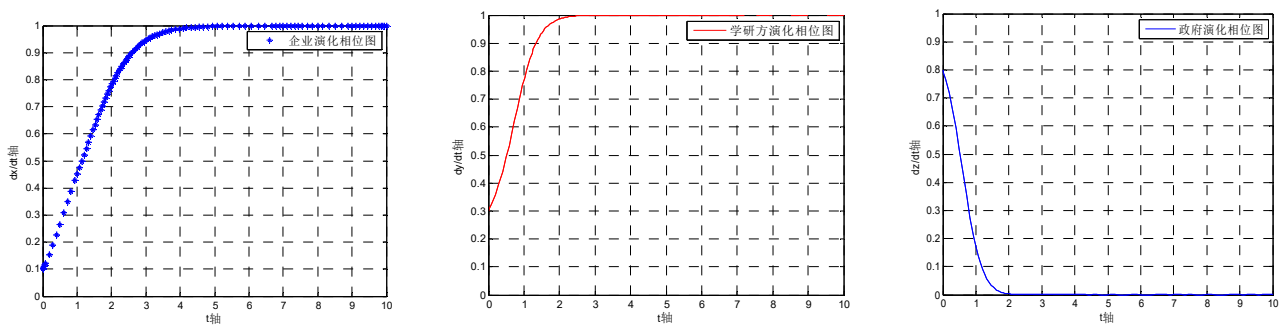

Fig2. Evolution phase diagrams of the three groups at each initial value

\section{Conclusions}

This paper builds regional innovation networks cooperative innovation mechanism in the process of 
evolution game. The participants mainly include government, enterprises, university and research institution. The result of the game shows that the stability mechanism cannot be achieved without the cooperation of any party, each participant's decision on whether to adopt synergetic innovation will have a significant influence on the dynamic evolution path and result.

The government's regulatory costs, subsidies from the government would affect the willingness and synergetic effect of collaborative innovation of enterprises and university and research; the profit resulting from synergetic innovation behaviour further influence synergetic innovation decisions; not coordination costs, government punishment, the synergistic decision of one party bring the other side of the other party's loss factors strand to synergetic innovation decision-making.

The cooperative parties of regional innovation network should establish network information management center. It should be able to improve procedures and systems for formal and informal communication associated with regional innovation networks, smooth communication channels to enhance the sensitivity and responsiveness of network information. Through improving the quality and efficiency of communication, cooperative enterprises in regional networks can increase cooperation opportunities, gain the right to take the initiative in cooperation, improve the breadth and depth of knowledge retrieval, and then strengthen knowledge sharing and mutual learning to improve absorption capacity.

As the carrier of regional innovation competition, the government should focus on the mechanism construction of promoting intra-regional coordination and extraregional cooperation and communication. It is necessary to formulate laws, policies and management regulations that belong to the regional industry- academic-research synergetic innovation in combination with regional characteristics. The policy subsidy and punishment mechanism will be used to enhance the impetus for the cooperation between the industry- academic-research institutes and guide the sound coordinated development of regional innovation network.

As the direct participant of regional synergetic innovation, the academic and research parties should give play to the advantages of regional talents ,resources ,knowledge and scientific research; improve the internal policies of scientific research cooperation, intellectual property right confirmation, protection ,transfer and sharing; break the institutional barriers that hinder openness and sharing; develop incentive and punitive measures to protect and promote the safety and initiative of personnel ,institutions and organizations working together to promote regional synergetic innovation capacity.

Enterprises should make full use of resources to establish institutions and systems for collecting, processing and integrating scientific, technological and market intelligence, strengthen research cooperation with schools and research institutes.

In brief, only in this way can the regional innovation network effectively play its role, promote integrated innovation, encourage breakthrough innovation, and enhance independent innovation capacity and innovation performance through collaboration.

\section{Acknowledgment}

National Natural Science Foundation of China $(61462060,61762060,71372196)$

\section{REFERENCES}

1. Kamla Ali Al-Busaidi, Lorne Olfman.Knowle-dge sharing through inter-organizational knowledge sharing systems[J]. VINE Journal of Information and Knowledge Management systems ,2016, (5) : 110136 .

2. Dechun Huang. Chinese Regional Innovation Capability Assessment and Trend Analysis: An Empirical Study based on THE PLS path Model [A]. Proceedings of the 6th (2011) Chinese Management Annual ConferenceTechnology and Innovation Management Conference [C] .

3. Cook p. Regional innovation systems, cluster and the knowledge economy[J]. Industrial and Corporate Change ,2001,10(3):945-975.

4. Hedan Ma. Research on Enterprise Knowledge Innovation based on Regional Innovation Network [J] . Academic Frontiers of People's Forum 2018 (5) : 92-95 .

5. Sang Lee ,David Olson ,Silvana Trimi . The Impact of Convergence on Organizational Innovation [J] . IEEE Engineering Management Review ,2013,41(3):58-66.

6. Jin Chen, Yinjuan Yang. Theoretical basis and connotation of synergetic innovation[J]. Research in science of science ,2012,30(2):161-164.

7. Yubing He. Theoretical model of industry-universityresearch collaborative innovation[J]. Research in science of science ,2012,30(2):165-174.

8. Jun-hua Li, Yao De, Yueming Cheng. The running mechanism of synergetic innovationin regional innovation network study [J]. Science and technology progress and countermeasures, 2012, (13):32-36.

9. ZhiJie Song, Hao Wang, Rui Shi. Across the drive mechanism of regional innovation resources synergy and synergy mode analysis [J]. Journal of enterprise economy, 2017, (02): 167-173.

10. Tsai W.,"Knowledge transfer in intra-organizational networks: effects of network position and absorptive capacity on business unit innovation and performance", Acade my of Management Journal ,2001 ,44 (5): pp .996-1004.

11. Ma Dalai, zhong-chang Chen, wang ling. Convergence of Regional Innovation Efficiency in China: From the Perspective of Spatial Economics [J]. Journal of Management:71-78.

12. Chuansi Yuan. New research in the subject role of industry technology alliance [J]. Science and technology management research, 2016, (9):112-115, 
125.

13. Linming Xu Qiubi Sun, Meijuan Li, Zhonghui Ou. Regional collaborative innovation capability of dynamic portfolio assessment [J]. Journal of statistics and decision, 2017, (9):68-70.

14. Hua Zhang. Evolutionary game mechanism research of collaborative innovation, knowledge overflow [J]. Journal of management science in China ,2016, (02): 92-99.

15. Yezhen Zhang, Xiang Lin. Industrial technology innovation strategy alliance evolutionary game analysis of cooperative innovation $[\mathrm{J}]$. Journal of fujian normal university (philosophy and social sciences edition), 2015,(02) : 22-30+167.

16. Jiaoping Yang, Nan Hou, Le Wang. Cluster knowledge spillover, knowledge, potential energy and cluster innovation performance in $[\mathrm{J}]$. Journal of management engineering, 2016, (3): 27-35.

17. Huainian Zhu, Guangyu zhang, Cheng-ke zhang, Yixin Liu, Shihui Yang. Opportunism under evolutionary game simulation analysis of cooperative innovation behavior [J]. Science and technology management research ,2016,(4):13-18 . 